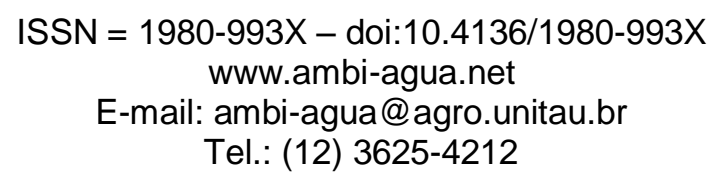

\title{
Consequências hidrológicas da mudança de uso da terra de floresta para pastagem na região da floresta tropical pluvial Atlântica
}

(http://dx.doi.org/10.4136/ambi-agua.927)

\author{
Luiz Felippe Salemi ${ }^{1}$; Juliano Daniel Groppo ${ }^{1}$; Rodrigo Trevisan ${ }^{1}$; \\ Gustavo Bicci Seghesi ${ }^{1}$; Jorge Marcos de Moraes $^{1,2}$; \\ Silvio Fronsini de Barros Ferraz ${ }^{1}$, Luiz Antonio Martinelli ${ }^{1}$ \\ ${ }^{1}$ Laboratório de Ecologia Isotópica - Centro de Energia Nuclear na Agricultura - \\ Universidade de São Paulo, Piracicaba - SP, Brasil, \\ emails: piposalemi@gmail.com, julianogroppo@yahoo.com.br, \\ rtrevisan@yahoo.com.br, gbseghesi@gmail.com, \\ jmmoraes@cena.usp.br, silvio.ferraz@usp.br, zebu@cena.usp.br \\ ${ }^{2}$ Escola de Engenharia de Piracicaba, Piracicaba - SP, Brasil
}

\section{RESUMO}

A floresta tropical pluvial Atlântica é um dos ecossistemas mais ameaçados do Brasil. A degradação deste grande ecossistema ocorre desde o descobrimento do país. Poucos estudos investigaram a hidrologia de microbacias na região deste bioma. A totalidade dos estudos existentes se restringe a ecossistemas cuja cobertura é de florestas naturais. Nesse contexto, este trabalho elucida as consequências hidrológicas da conversão de floresta em pastagem nos domínios da floresta atlântica ombrófila densa. Para tanto, foram medidos o escoamento superficial, a vazão, a condutividade hidráulica do solo, o potencial matricial da água do solo de uma microbacia coberta por pastagem durante um ano. Os resultados indicam que a conversão de floresta ombrófila densa para pastagem promove a redução da condutividade hidráulica próximo à superfície do solo. Entretanto, como as chuvas predominantes são de baixa intensidade, essa redução na permeabilidade do solo à água não implica necessariamente em um aumento substancial de escoamento superficial. Em relação ao potencial matricial da água do solo, a pastagem apresentou valores sempre maiores que os da floresta durante a estação seca. Esse aumento da umidade do solo sobre o uso de pastagens implica em maior drenagem de água rumo ao lençol freático. Este fato explica os maiores valores do coeficiente de deflúvio. Assim, ao converter uma microbacia coberta por Floresta Tropical Atlântica em pastagem, espera-se uma maior conversão de chuva em vazão em termos anuais. Todavia, o aumento do deflúvio ocorre em detrimento da altíssima biodiversidade e da alta proteção do solo quando o solo está coberto por florestas.

Palavras-chave: Floresta Atlântica, água, solo, recursos hídricos.

\section{Hydrological consequences of land-use change from forest to pasture in the Atlantic rain forest region}

\begin{abstract}
The Atlantic rain forest is the most endangered ecosystem in Brazil. Its degradation has started since 1500 when the European settlers arrived. Despite of all land use changes that have occurred, hydrological studies carried out in this biome have been limited to hydrological functioning of rain forests only. In order to understand the hydrological consequences of land-use change from forest to pasture, we described the hydrological
\end{abstract}


SALEMI, L. F.; GROPPO, J. D.; TREVISAN, R.; SEGHESI, G. B.; MORAES, J. M.; FERRAZ, S. F. B.; MARTINELLI, L. A. Consequências hidrológicas da mudança de uso da terra de floresta para pastagem na região da floresta tropical pluvial atlântica. Ambi-Agua, Taubaté, v. 7, n. 3, p. 127-140, 2012. (http://dx.doi.org/10.4136/ambi-agua.927)

functioning of a pasture catchment that was previously covered by tropical rain forest. To reach this goal we measured the precipitation, soil matric potential, discharge, surface runoff and water table levels during one year. The results indicated that there is a decrease in surface soil saturated hydraulic conductivity. However, as low intensity rainfall prevails, the lower water conductivity does not necessarily leads to a substantially higher surface runoff generation. Regarding soil water matric potential, the pasture presented higher moisture levels than forest during the dry season. This increase in soil moisture implies in higher water table recharge that, in turn, explain the higher runoff ratio. This way, land-use change conversion from forest to pasture implies a higher annual streamflow in pasture catchments. Nonetheless, this increase in runoff due to forest conversion to pasture implies in losses of biological diversity as well as lower soil protection.

Keywords: Atlantic Forest, water, soil, water resources.

\section{INTRODUÇÃO}

A Mata Atlântica é o bioma mais ameaçado do Brasil (Schaffer e Prochnow, 2002). A degradação deste grande ecossistema vem ocorrendo desde o descobrimento do país (Dean, 1996; Bueno, 2006) e a supressão da vegetação, que originalmente cobria cerca de 1.300.000 $\mathrm{km}^{2}$, reduziu este sistema natural a uma área descontínua de aproximadamente $98.800 \mathrm{~km}^{2}$, isto é, 7,6\% da sua extensão original (Morellato e Haddad, 2000). Estas florestas foram cortadas para obtenção de madeira, lenha, carvão vegetal, assim como para ceder espaço para a agricultura, a criação de gado e a expansão de centros urbanos (Morellato e Haddad, 2000).

A floresta atlântica é composta principalmente por dois tipos de vegetação: a Floresta Pluvial Atlântica que se estende por quase toda a costa atlântica brasileira e a Floresta Estacional Semidecidual que se estende em direção ao interior do Brasil (Morellato e Haddad, 2000). O primeiro tipo de vegetação também é chamado de floresta ombrófila densa. O termo "ombrófila" caracteriza florestas que se distribuem geograficamente em locais de alta pluviosidade anual. Esta fitofisionomia cobre toda a Serra do Mar e a planície costeira. Poucos estudos investigaram a hidrologia de microbacias nesta região. A maioria das publicações existentes se limitam à região de Cunha - SP devido à existência de infraestrutura e equipamentos para tanto (Arcova e Cicco, 1997; Fujieda et al., 1997; Anido, 2002; Arcova et al., 2003; Ranzini et al., 2004a, b; Donato et al., 2008). Entretanto, exceções são feitas aos trabalhos de Coelho Neto (1987) e Groppo (2010) realizados na Floresta Ombrófila Densa do Rio de Janeiro - RJ e de São Luiz do Paraitinga - SP, respectivamente. Contudo, todos esses estudos se restringem apenas a ecossistemas cuja cobertura é constituída de florestas naturais.

Nesse contexto, buscando contribuir para o entendimento das consequências hidrológicas das mudanças de uso da terra nos domínios da floresta atlântica ombrófila, o presente trabalho pretende descrever o funcionamento hidrológico de uma microbacia coberta por pastagem que outrora fora previamente coberta por floresta ombrófila. Em etapa subsequente, ao se comparar os resultados obtidos aos resultados disponíveis na literatura, tenta-se entender as consequências da mudança de uso da terra de floresta para pastagem nesta região.

\section{MATERIAIS E MÉTODOS}

\subsection{Localização da área}

A microbacia estudada situa-se no bairro Vargem Grande, município de Natividade da Serra - SP e possui área equivalente a 4,7 ha. A altitude média é de 860 metros. A bacia 
SALEMI, L. F.; GROPPO, J. D.; TREVISAN, R.; SEGHESI, G. B.; MORAES, J. M.; FERRAZ, S. F. B.; MARTINELLI, L. A. Consequências hidrológicas da mudança de uso da terra de floresta para pastagem na região da floresta tropical pluvial atlântica. Ambi-Agua, Taubaté, v. 7, n. 3, p. 127-140, 2012. (http://dx.doi.org/10.4136/ambi-agua.927)

constitui uma sub-bacia do rio Paraibuna e o canal fluvial é classificado como de segunda ordem (Figura 1).

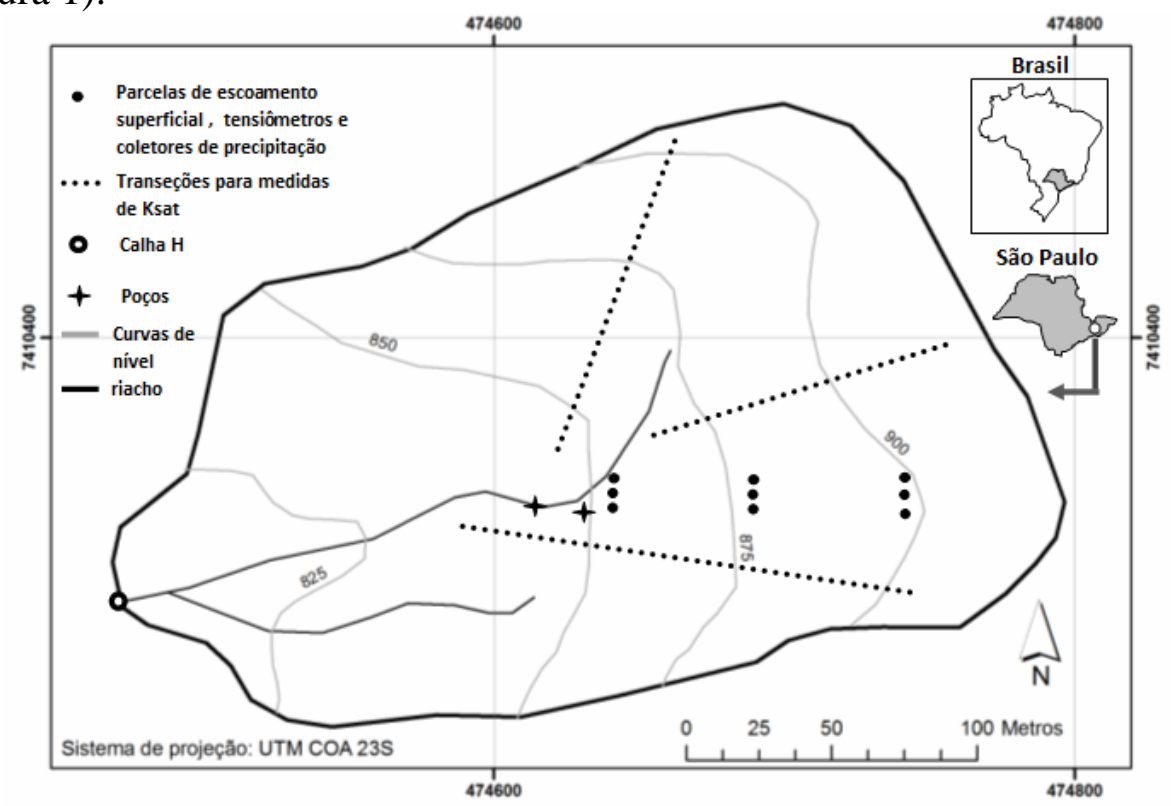

Figura 1. Localização da microbacia utilizada do presente estudo e o delineamento do experimento.

No tocante ao clima, a pluviosidade anual média de Natividade da Serra, distante cerca de $20 \mathrm{~km}$ da área de estudo, é de $1800 \mathrm{~mm}$ (Folhes et al., 2007) podendo haver zonas com menor precipitação $(1300$ a $1500 \mathrm{~mm})$. Em relação à temperatura, as médias mínima e máxima são de, respectivamente, 3 e $26^{\circ} \mathrm{C}$ com média de $17^{\circ} \mathrm{C}$.

Acerca do histórico do uso da terra, este foi obtido por meio de entrevista com os atuais proprietários e moradores locais. De acordo com a descrição, em 1963 houve a conversão de floresta para a cultura de milho e outras, além do cultivo de espécies frutíferas (laranja e limão). Durante este período, não houve preparo do solo com máquinas e implementos. Apenas trabalhos manuais com enxada foram executados. A conversão do uso do solo ocorreu por meio do processo de corte e da queima. De 1968 aos dias atuais, o uso do solo foi convertido para pastagem restando apenas poucas árvores frutíferas do antigo uso da terra. A pastagem possui taxa de lotação de 2,5 cabeças por hectare. A espécie de gramínea predominante é Brachiaria decumbens Stapf. Contudo, há a presença de plantas invasoras herbáceas e arbóreas.

Os solos da microbacia são classificados como cambissolos háplicos distróficos e são derivados da alteração de gnaisses. Contudo, nas regiões adjacentes ao canal fluvial, os solos são classificados como gleissolos.

\subsection{Delineamento experimental}

O delineamento do experimento é ilustrado na Figura 1. Foram usados três coletores de precipitação e nove parcelas de escoamento superficial dispostas de forma que três foram instaladas na porção mais baixa da vertente, três na porção central e três na parte superior. Cada uma das parcelas possuia $2,25 \mathrm{~m}^{2}$ de área e foi delimitada por placas de madeira com um tubo de PVC de 1,5 m na cota mais baixa atuando como coletor de água. Para não sofrer influência direta da precipitação incidente, o coletor foi coberto por uma lona de plástico. Mais detalhes podem ser encontrados em Salemi (2009).

Nas mesmas três porções da encosta foram instalados tensiômetros a 15, 30, 50 e $90 \mathrm{~cm}$ de profundidade para entender o comportamento da umidade do solo. 
SALEMI, L. F.; GROPPO, J. D.; TREVISAN, R.; SEGHESI, G. B.; MORAES, J. M.; FERRAZ, S. F. B.; MARTINELLI, L. A. Consequências hidrológicas da mudança de uso da terra de floresta para pastagem na região da floresta tropical pluvial atlântica. Ambi-Agua, Taubaté, v. 7, n. 3, p. 127-140, 2012. (http://dx.doi.org/10.4136/ambi-agua.927)

Para monitorar o lençol freático, dois poços foram instalados, um em área adjacente ao rio e o outro a cerca de 20 metros de distância do mesmo.

No que tange à vazão, esta foi monitorada por meio de uma calha $\mathrm{H}$. Nesta calha há um poço de tranquilização em que foi instalado um sensor eletrônico de nível de água ("Water Level Sensor", Trutrack) que registrava a altura da lâmina de água da calha H em intervalos de 5 minutos. Deste modo, a descarga foi calculada desde 29 de novembro de 2007 até 29 de outubro de 2008, aplicando a altura da água medida em metros na equação disponível em Gwinn e Parsons (1976).

Todas as variáveis mencionadas, exceto a vazão que foi medida continuamente, foram monitoradas em base semanal de 29 de novembro de 2007 até 29 de outubro de 2008.

\subsection{Densidade do solo e condutividade hidráulica do solo em condição de saturação}

A condutividade hidráulica do solo em condição de saturação $\left(\mathrm{K}_{\text {sat }}\right)$ foi medida com o auxílio de um permeâmetro de carga constante ("Amoozemeter"). As profundidades de medição foram $15,30,50$ e $90 \mathrm{~cm}$. Ao final da medição totalizou-se 25 pontos de medição de $\mathrm{K}_{\mathrm{sat}}$ em cada profundidade.

A densidade do solo foi obtida por meio do uso do trado Uhland. Foram coletadas três amostras não deformadas nas mesmas profundidades que foram realizadas as medidas de $\mathrm{K}_{\text {sat }}$.

\subsection{Precipitação: análise da frequências de intensidades}

A quantificação da precipitação, bem como a análise da frequência de intesidade de chuva foram realizadas através da instalação de um pluviógrafo do tipo "tipping-bucket" (Rain Wise) que registra o volume de chuva $(\mathrm{mm})$ a cada 5 minutos.

\section{RESULTADOS E DISCUSSÃO}

A precipitação total durante o período de estudo foi de aproximadamente $1.433 \mathrm{~mm}$. Deste valor, $77 \%$ dos registros foram considerados de baixa intensidade, ou seja, variando de 0 a $5 \mathrm{~mm} \mathrm{~h}^{-1}$ (Figura 2). Esta classe de intensidade contribui em termos totais com cerca de $48 \%$ da precipitação total (Figura 2). Ao considerar o intervalo de 0 a $15 \mathrm{~mm} . \mathrm{h}^{-1}$, a contribuição aumenta para $70 \%$. Por outro lado, eventos com intensidades altas ocorrem com baixa frequência, sendo, em relação aos eventos de baixa intensidade, muito menos representativos.

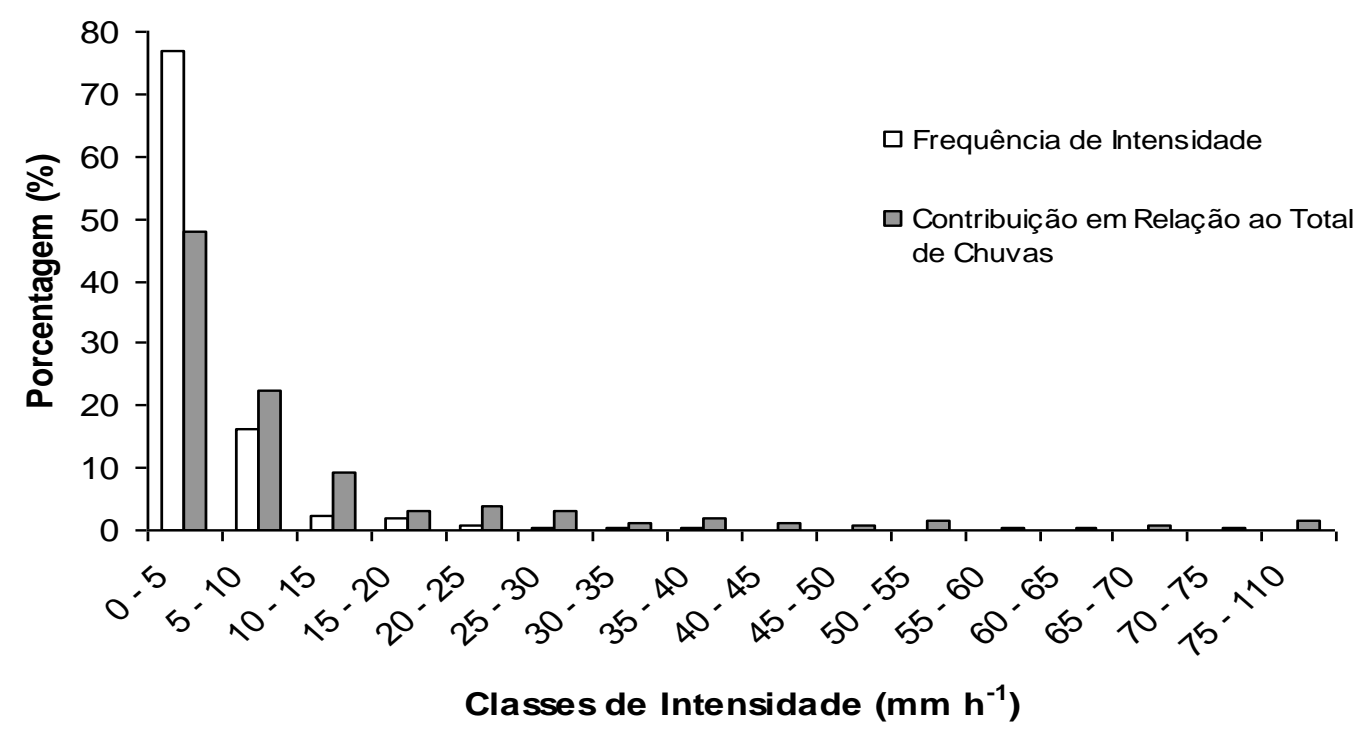

Figura 2. Distribuição de precipitação em classes de intensidade e sua contribuição para o total de chuvas. 
SALEMI, L. F.; GROPPO, J. D.; TREVISAN, R.; SEGHESI, G. B.; MORAES, J. M.; FERRAZ, S. F. B.; MARTINELLI, L. A. Consequências hidrológicas da mudança de uso da terra de floresta para pastagem na região da floresta tropical pluvial atlântica. Ambi-Agua, Taubaté, v. 7, n. 3, p. 127-140, 2012. (http://dx.doi.org/10.4136/ambi-agua.927)

A densidade do solo variou de 1,33 a $1,58 \mathrm{Mg} \mathrm{m}^{-3}$ (Figura 3). A título de comparação, podem-se observar também os dados de densidade obtidos em uma floresta ombrófila densa em área próxima à da pastagem aqui relatada disponível em Groppo (2010).

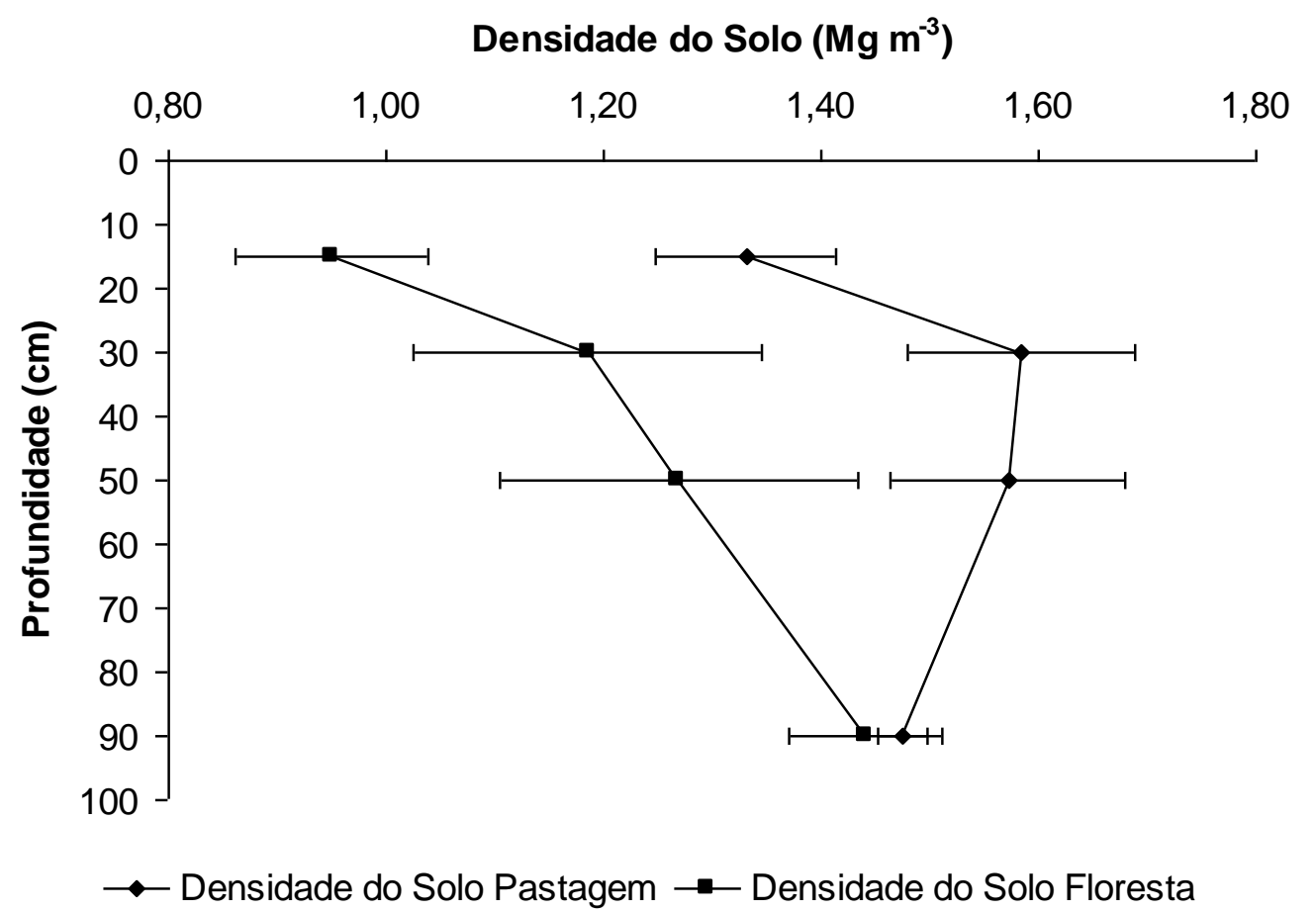

Figura 3. Densidade do solo a 15, 30, 50 e $90 \mathrm{~cm}$ de profundidade na pastagem e floresta.

As medidas de $\mathrm{K}_{\text {sat }}$ apresentaram mediana de $22,6,0,4$ e $0,2 \mathrm{~mm} \mathrm{~h}^{-1}$ respectivamente para 15, 30, 50 e $90 \mathrm{~cm}$ de profundidade (Figura 4).

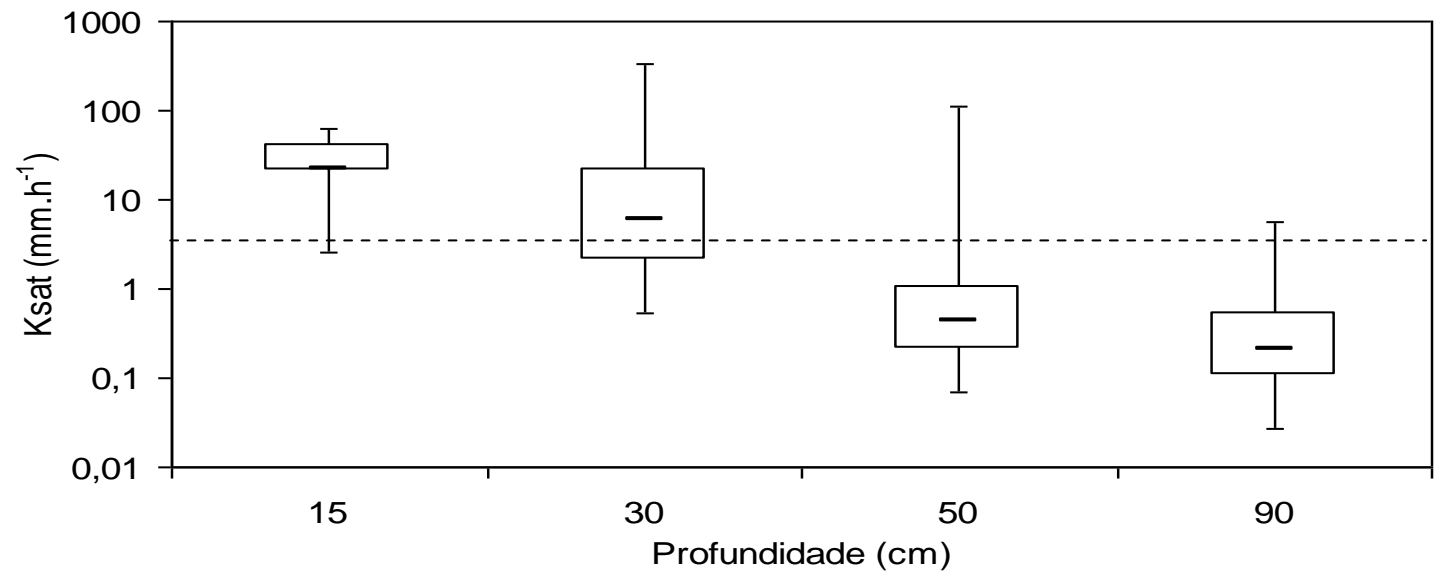

Figura 4. Diagrama de caixas exibindo a condutividade hidráulica do solo em condição de saturação $\left(\mathrm{K}_{\mathrm{sat}}\right)$ na profundidade de $15,30,50$ e $90 \mathrm{~cm}$ na pastagem. A linha pontilhada na horizontal representa a intensidade de chuva de $5 \mathrm{~mm} \mathrm{~h}^{-1}$ que é a mais representativa da região de estudo. 
SALEMI, L. F.; GROPPO, J. D.; TREVISAN, R.; SEGHESI, G. B.; MORAES, J. M.; FERRAZ, S. F. B.; MARTINELLI, L. A. Consequências hidrológicas da mudança de uso da terra de floresta para pastagem na região da floresta tropical pluvial atlântica. Ambi-Agua, Taubaté, v. 7, n. 3, p. 127-140, 2012. (http://dx.doi.org/10.4136/ambi-agua.927)

Nota-se que os valores de $\mathrm{K}_{\text {sat }}$, assim como outros atributos do solo, apresentaram uma grande variabilidade, fato já registrado em outros trabalhos (e.g. Moraes et al., 2006).

Ao comparar os valores de $\mathrm{K}_{\text {sat }}$ da pastagem medidos no presente estudo aos valores obtidos em outras pastagens, nota-se que as medianas de $\mathrm{K}_{\text {sat }}$ são muito próximas entre si, exceção feita aos trabalhos de Elsenbeer et al. (1999) e Moraes et al. (2006) (Tabela 1).

Tabela 1. Comparação dos valores da mediana de $\mathrm{K}_{\mathrm{sat}}\left(\mathrm{mm} \mathrm{h}^{-1}\right)$ em várias profundidades entre vários estudos.

\begin{tabular}{|c|c|c|c|c|}
\hline \multirow{2}{*}{\begin{tabular}{|l} 
Região do estudo \\
Amazônia $^{1}$
\end{tabular}} & \multicolumn{4}{|c|}{ Valores de mediana de Ksat $\left(\mathrm{mm} \mathrm{h}^{-1}\right)$} \\
\hline & $15 \mathrm{~cm}$ & $30 \mathrm{~cm}$ & $50 \mathrm{~cm}$ & $90 \mathrm{~cm}$ \\
\hline Pastagem & 13,00 & 6,00 & 0,80 & 0,70 \\
\hline Floresta & 71,00 & 13,00 & 11,00 & 12,00 \\
\hline Amazônia $^{2}$ & $12,5 \mathrm{~cm}$ & $30 \mathrm{~cm}$ & $50 \mathrm{~cm}$ & \\
\hline Pastagem abandonada & 21,00 & 17,00 & 33,00 & \\
\hline Floresta & 270,00 & 25,00 & 5,00 & \\
\hline Amazônia ${ }^{3}$ & $15 \mathrm{~cm}$ & $30 \mathrm{~cm}$ & $50 \mathrm{~cm}$ & $90 \mathrm{~cm}$ \\
\hline Pastagem & 7,00 & 4,00 & 8,00 & 0,08 \\
\hline Floresta & 310,00 & 35,00 & 8,00 & 1,00 \\
\hline Amazônia ${ }^{4}$ & $12,5 \mathrm{~cm}$ & $20 \mathrm{~cm}$ & & \\
\hline Pastagem & 22,00 & 6,00 & & \\
\hline Floresta & 131,00 & 22,00 & & \\
\hline Mata Atlântica & $15 \mathrm{~cm}$ & $30 \mathrm{~cm}$ & $50 \mathrm{~cm}$ & $90 \mathrm{~cm}$ \\
\hline Pastagem 5 & 22,00 & 6,00 & 0,40 & 0,20 \\
\hline Floresta $^{6}$ & 60,00 & 8,00 & 2,00 & 4,00 \\
\hline
\end{tabular}

Fontes: ${ }^{1}$ Elsenbeer et al. (1999) - Latossolo; ${ }^{2}$ Godsey e Elsenbeer (2002) - Argissolo; ${ }^{3}$ Moraes et al. (2006) Solos plínticos; ${ }^{4}$ Zimmermann et al. (2006) - Latossolo e ${ }^{5}$ presente estudo - Cambissolo; ${ }^{6}$ Groppo (2010) Cambissolo.

Em comparação ao estudo conduzido em área de floresta ombrófila densa na mesma região do presente estudo (Groppo, 2010), a floresta teve seu valor de $\mathrm{K}_{\text {sat }}$ próximo à superfície (15 cm de profundidade) claramente maior que o da pastagem $\left(60\right.$ e $22 \mathrm{~mm} \mathrm{~h}^{-1}$ respectivamente) (Tabela 1). Esse fato decorre do intenso pisoteio do gado que tem um efeito de provocar a compactação do solo (Reiners et al., 1994; Moraes et al., 1996). Em consonância com a literatura, a densidade do solo da pastagem do presente estudo é claramente maior se comparado à da floresta (Figura 3).

Fujieda et al. (1997) relatam também altos valores de $\mathrm{K}_{\text {sat }}$ próximo à superfície do solo de uma floresta ombrófila densa localizada em Cunha - SP variando de 35 a $350 \mathrm{~mm} \mathrm{~h}^{-1}$. Estes valores são próximos aos disponíveis em Groppo (2010) em uma microbacia com o mesmo tipo de floresta em São Luiz do Paraitinga - SP.

$\mathrm{Na}$ profundidade de $50 \mathrm{~cm}$, a pastagem e a floresta (Groppo, 2010) apresentam valores de $\mathrm{K}_{\text {sat }}$ extremamente reduzidos, embora a floresta ainda tenha valores cinco vezes maiores.

O potencial matricial da água do solo medido nas profundidades de 15, 30, 50 e $90 \mathrm{~cm}$ em três locais da vertente (topo, meio e sopé) teve amplitude de 0 a $-87 \mathrm{kPa}$. No entanto, de maneira geral, percebe-se que a maior parte do ano o solo, em todas as porções da encosta, permanece em estados de alto grau de umidade, isto é, com potencial matricial variando de 0 a $-8 \mathrm{kPa}$ (Figura 5). Apesar de haver variabilidade no potencial da água do solo nas quatro profundidades, de uma maneira geral, o solo permaneceu em condições muito úmidas por 
SALEMI, L. F.; GROPPO, J. D.; TREVISAN, R.; SEGHESI, G. B.; MORAES, J. M.; FERRAZ, S. F. B.; MARTINELLI, L. A. Consequências hidrológicas da mudança de uso da terra de floresta para pastagem na região da floresta tropical pluvial atlântica. Ambi-Agua, Taubaté, v. 7, n. 3, p. 127-140, 2012. (http://dx.doi.org/10.4136/ambi-agua.927)

longos períodos (Reichardt, 1988). Foi possível notar que há variabilidade espacial na umidade nas mesmas datas de medição. Tal variação está de acordo com o que outros autores encontraram para pastagens e pode ser atribuído à variação espacial da compactação do solo (Hodnett et al., 1995).

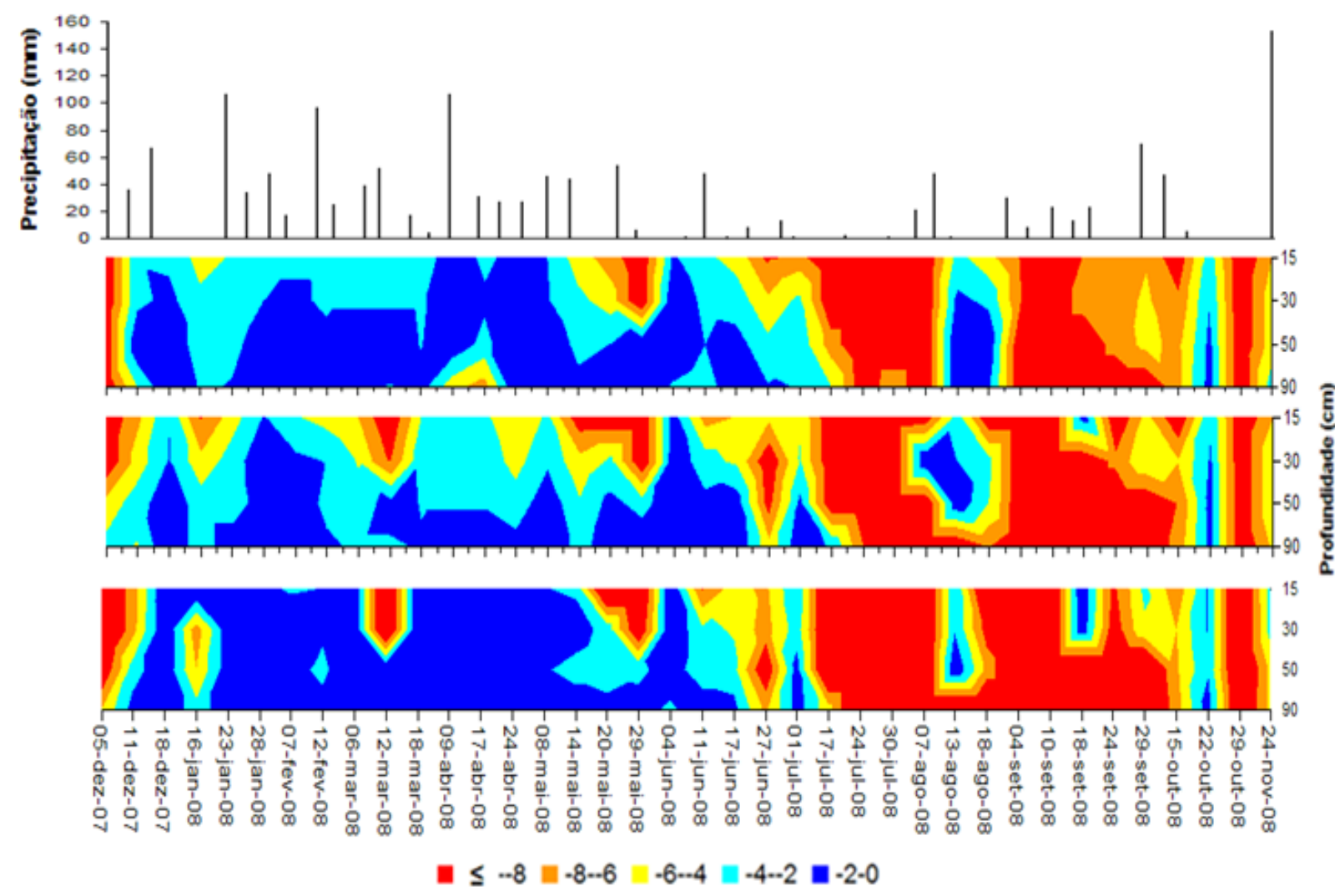

Figura 5. Precipitação semanal e classes de potencial matricial da água no solo $(\mathrm{kPa})$ da vertente (Superior - sopé; intermediário - meio da vertente ; e inferior - porção mais alta da vertente).

Ao comparar o potencial matricial da água do solo na pastagem ao da floresta ombrófila densa estudada por Groppo (2010), nota-se que durante os períodos chuvosos, não há diferença marcante no potencial matricial da água do solo. Esta similaridade permite inferir que a diferença de cobertura vegetal tem pouca influência sobre a umidade do solo que rapidamente é reposta pelas chuvas de baixa intensidade. Porém, se somente o período seco (junho a agosto) for analisado, observa-se que a floresta exibe potenciais matriciais muito mais baixos (negativos). Esse fato também foi observado por vários outros autores comparando florestas e pastagens (Nepstad et al., 1994; Jipp et al., 1998; Moraes et al., 2006). Em todos os estudos mencionados bem como na comparação feita em relação ao trabalho realizado por Groppo (2010), a absorção pelo sistema radicular mostrou-se muito mais vigorosa na floresta do que nas pastagens durante a estação seca, o que reflete as diferenças de uso da água pelas diferentes comunidades vegetais que possuem estrutura e metabolismo distintos.

No que se refere ao coeficiente de escoamento superficial, o valor médio calculados das nove parcelas instaladas (Tabela 2) equivalente a 0,02 , ou seja, cerca de $2 \%$ da precipitação tornou-se escoamento superficial.

Ao utilizar o mesmo delineamento de parcelas de escoamento superficial em floresta ombrófila densa, Groppo (2010) apresentou valores de coeficiente de escoamento superificial inferiores a $1 \%$. Se comparado aos resultados do presente estudo, um pouco mais que o dobro 
SALEMI, L. F.; GROPPO, J. D.; TREVISAN, R.; SEGHESI, G. B.; MORAES, J. M.; FERRAZ, S. F. B.; MARTINELLI, L. A. Consequências hidrológicas da mudança de uso da terra de floresta para pastagem na região da floresta tropical pluvial atlântica. Ambi-Agua, Taubaté, v. 7, n. 3, p. 127-140, 2012. (http://dx.doi.org/10.4136/ambi-agua.927)

do volume da chuva é convertido em escoamento superficial quando se converte floresta para pastagem.

Tabela 2. Média e amplitude do coeficiente de escoamento superficial nas três porções da vertente da microbacia. Os valores se referem às parcelas situadas nas três porções da encosta.

\begin{tabular}{c|cc}
\hline Porção da vertente & Média & Amplitude \\
\hline Inferior & 0,016 & $0-0,44$ \\
Média & 0,006 & $0-0,18$ \\
Superior & 0,017 & $0-0,52$ \\
\hline
\end{tabular}

As chuvas de baixa intensidade não excedem a $\mathrm{K}_{\text {sat }}$ próximo à superfície, o que permite que a água pluvial se infiltre e se redistribua mantendo baixos os valores de potencial matricial (Figura 5). Essa inferência baseia-se nos resultados baixos dos coeficientes de escoamento superficial obtido nas parcelas (Tabela 2). No entanto, nota-se grandes amplitudes já que em alguns eventos cerca de $44 \%$ da precipitação é convertida em escoamento superficial na porção inferior da vertente. Contudo, eventos pluviais que produzem essa magnitude de escoamento superficial são raros (Figura 2).

Para elucidar o conjunto de processos hidrológicos de superfície que ocorrem durante eventos de chuva, foram selecionados dois eventos extremos (Figura 6a e 6b). O primeiro representa a geração de escoamento direto em condições chuvas de baixa intensidade que são típicas da região $\left(0\right.$ a $\left.5 \mathrm{~mm} \mathrm{~h}^{-1}\right)$. $\mathrm{O}$ segundo evento, menos frequente, possui intensidade de chuva máxima que se enquadra na classe de chuvas fortes ou pesadas (35 a $40 \mathrm{~mm} \mathrm{~h}^{-1}$ ) (Hewlett, 1982).

Na Figura 6a, nota-se que há um pequeno aumento da vazão ao longo do evento de chuva. De fato, esse incremento ocorre principalmente devido à geração de escoamento subsuperficial das áreas adjacentes ao canal como descrito por Dunne (1978). Há também, embora em menor proporção, uma contribuição de escoamento superficial hortoniano em trilhas que se dirigem ao canal. O escoamento direto foi obtido por meio da separação de hidrogramas seguindo método da linha reta encontrado em Chow et al. (1988). Desse modo, em relação à Figura $6 \mathrm{a}$, em termos totais, o escoamento direto representou $7 \%$ do escoamento total. De maneira coerente, a resposta hidrológica (volume em $\mathrm{mm}$ de escoamento direto / precipitação do evento medida em $\mathrm{mm}$ ) foi de $1,4 \%$. Ademais, o tempo de pico, entendido como intervalo de tempo entre o máximo valor de intensidade de precipitação e o máximo valor de vazão no hidrograma, é de aproximadamente 1 hora.

Por outro lado, observa-se que as altas intensidades de chuva fazem com que várias áreas da microbacia produzam escoamento superficial hortoniano e de áreas saturadas, produzindo um aumento expressivo da vazão, assim como apresentando tempo de pico de 20 minutos, que é mais rápido do que o apresentado na Figura 6a. No hidrograma apresentado na Figura $6 \mathrm{~b}$, o escoamento direto representou $31 \%$ do escoamento total. Além disso, a resposta hidrológica foi de 6\%. Esse valor, se comparado ao do hidrograma da Figura 6a, é expressivamente mais elevado.

A principal via hidrológica que compõem o deflúvio é o escoamento de base já que a curva de duração de fluxo apresenta-se uma inclinação suave em quase toda a sua extensão (Figura 7). Esta informação está em consonância com os baixos coeficientes de escoamento superficial obtidos a partir das parcelas, bem como os altos valores de umidade do solo. 
SALEMI, L. F.; GROPPO, J. D.; TREVISAN, R.; SEGHESI, G. B.; MORAES, J. M.; FERRAZ, S. F. B.; MARTINELLI, L. A. Consequências hidrológicas da mudança de uso da terra de floresta para pastagem na região da floresta tropical pluvial atlântica. Ambi-Agua, Taubaté, v. 7, n. 3, p. 127-140, 2012. (http://dx.doi.org/10.4136/ambi-agua.927)

a)

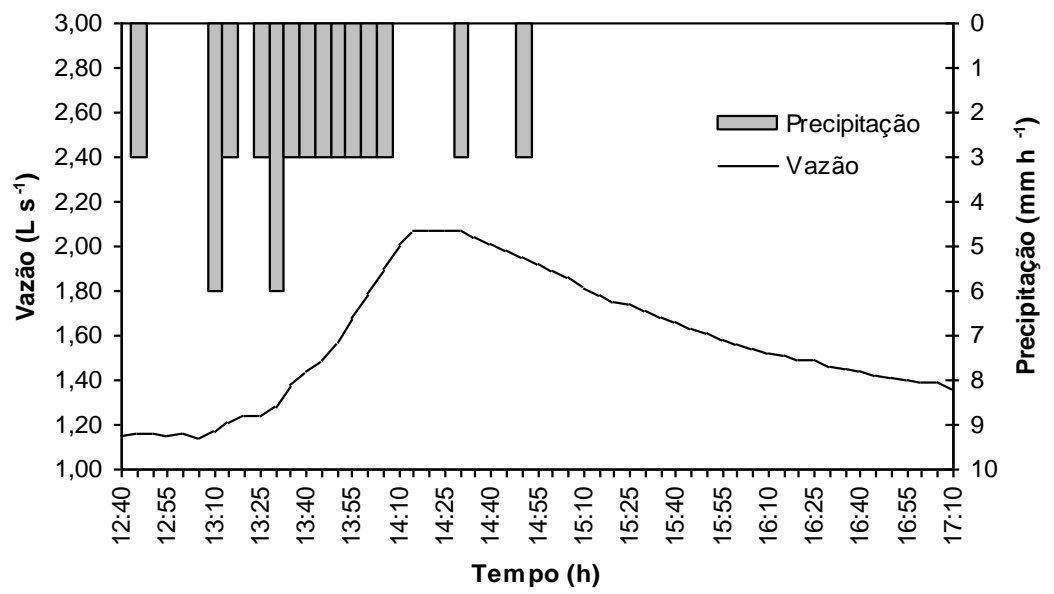

b)

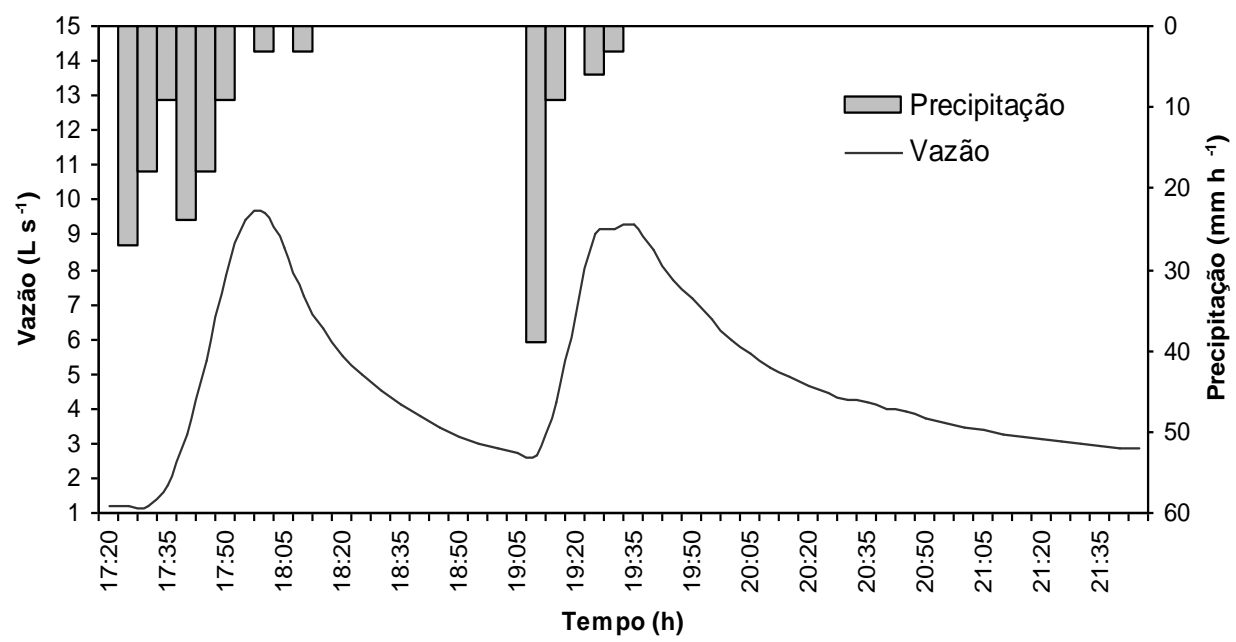

Figura 6. Hidrogramas e hietogramas exibindo geração de escoamento direto (a) evento de precipitação de intensidade leve e (b) evento de precipitação de intensidade forte.

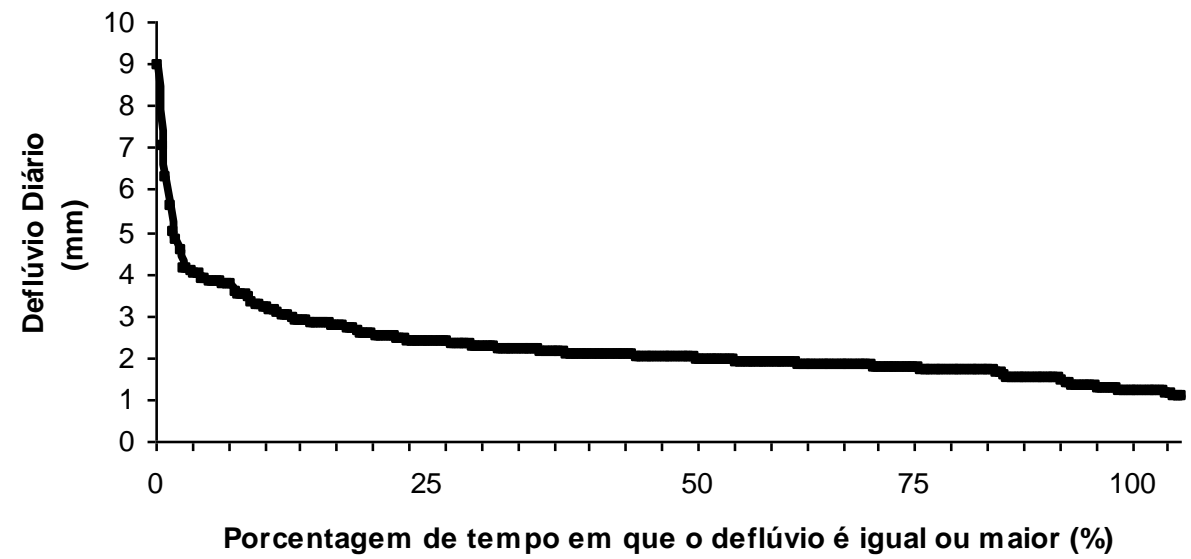

Figura 7. Curva de duração de fluxo. 
SALEMI, L. F.; GROPPO, J. D.; TREVISAN, R.; SEGHESI, G. B.; MORAES, J. M.; FERRAZ, S. F. B.; MARTINELLI, L. A. Consequências hidrológicas da mudança de uso da terra de floresta para pastagem na região da floresta tropical pluvial atlântica. Ambi-Agua, Taubaté, v. 7, n. 3, p. 127-140, 2012. (http://dx.doi.org/10.4136/ambi-agua.927)

O deflúvio anual para o período de estudo totalizou $736 \mathrm{~mm}$. Ao subtrair o valor do deflúvio anual a precipitação anual $(1433 \mathrm{~mm})$, obteve-se a evapotranspiração de $697 \mathrm{~mm}$ $a^{-1}$. Essa estimativa de evapotranspiração anual apresentou um valor muito próximo do que Zhang et al. (2001) modelaram (aproximadamente $700 \mathrm{~mm}^{-1}$ ).

Com a precipitação anual e o deflúvio anual calculou-se o coeficiente de deflúvio entendido aqui como a razão entre a evapotranspiração e a precipitação ambos em base anual. Dessa forma, a razão obtida foi de 0,51 , sugerindo que $51 \%$ da precipitação se transforma em deflúvio sendo o restante perdido por evapotranspiração.

O coeficiente de deflúvio obtido no presente estudo, se comparado ao deflúvio gerado em uma microbacia florestal na mesma região (Groppo, 2010), é substancialmente maior (Tabela 3). De fato, o coeficiente mostra que as árvores das florestas consomem mais água do que as gramíneas das pastagens (Brown et al., 2005). O mesmo foi encontrado, em Paragominas - PA, por Moraes et al. (2006) ao estudar microbacias cobertas por floresta e pastagem drenadas por canais efêmeros.

De maneira diferente, ao comparar estudos como o de Fujieda et al. (1997) realizado na floresta atlântica ombrófila em Cunha - SP, há uma notável divergência. Estes autores encontraram o coeficiente de 0,7 para uma microbacia coberta por floresta nativa. Esse valor, se comparado ao encontrado no presente estudo, é surpreendente já que a floresta teria uma evapotranspiração menor que a de uma pastagem, situação essa que discorda da grande maioria dos estudos de microbacias pareadas (Zhang et al., 2001) e que também difere do resultado encontrado por Groppo (2010). No entanto, Donato et al. (2008) também avaliaram a evapotranspiração das mesmas bacias que Fujieda et al. (1997) e encontraram um coeficiente levemente inferior ao destes autores, mas ainda superior ao da pastagem do presente estudo (Tabela 3).

Tabela 3. Comparação entre os coeficientes de deflúvio obtidos em vários experimentos realizados em microbacias hidrográficas com usos do solo de floresta e pastagem.

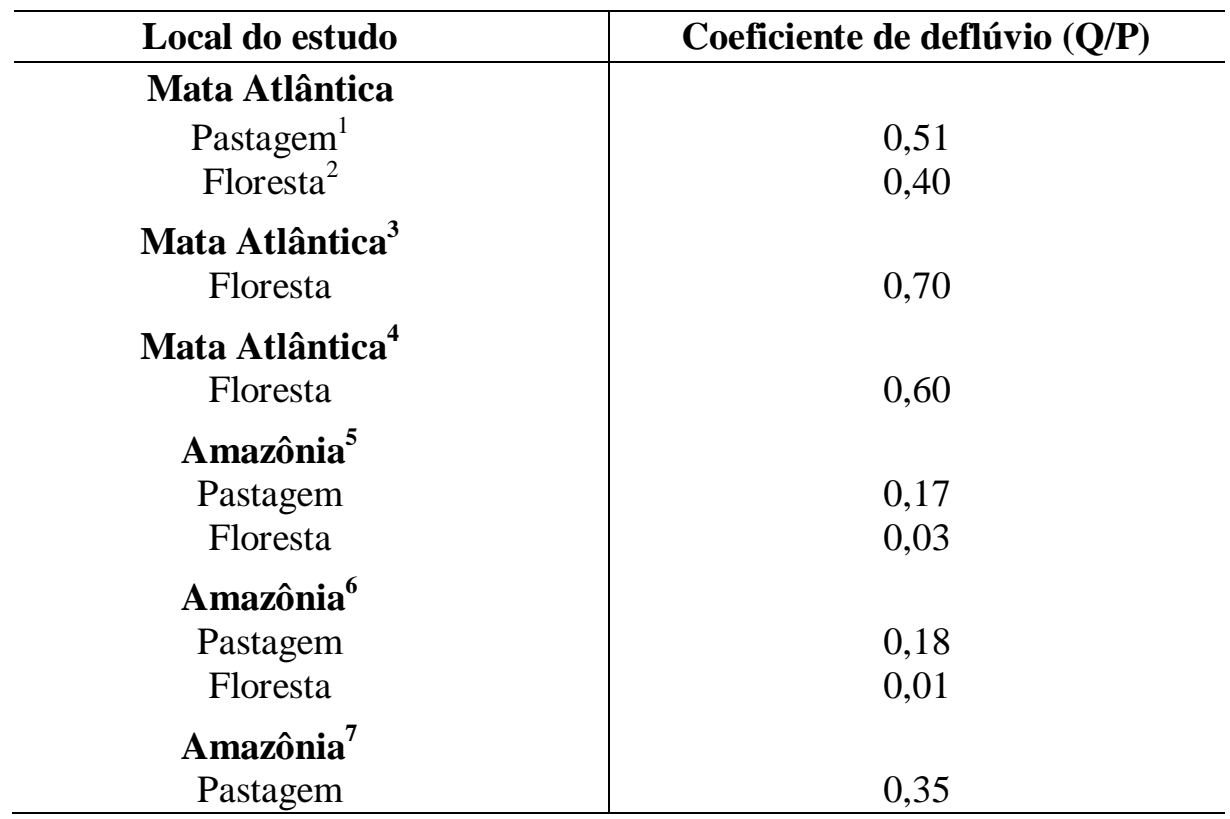

Fontes: ${ }^{1}$ presente estudo; ${ }^{2}$ Groppo (2010); ${ }^{3}$ Fujieda et al. (1997); ${ }^{4}$ Donato et al. (2008); ${ }^{5}$ Moraes et al. (2006); ${ }^{6}$ Germer et al. (2009) e ${ }^{7}$ Biggs et al. (2006). 
SALEMI, L. F.; GROPPO, J. D.; TREVISAN, R.; SEGHESI, G. B.; MORAES, J. M.; FERRAZ, S. F. B.; MARTINELLI, L. A. Consequências hidrológicas da mudança de uso da terra de floresta para pastagem na região da floresta tropical pluvial atlântica. Ambi-Agua, Taubaté, v. 7, n. 3, p. 127-140, 2012. (http://dx.doi.org/10.4136/ambi-agua.927)

\section{CONCLUSÃO}

A conversão de floresta ombrófila densa para pastagem na região da floresta tropical pluvial atlântica promove a redução da condutividade hidráulica próximo à superfície do solo. Entretanto, como as chuvas predominantes são de baixa intensidade, essa redução da permeabilidade do solo à água não implica necessariamente em um aumento substancial de escoamento superficial e de processos erosivos associados a esta via hidrológica.

Em relação ao potencial matricial da água do solo, as pastagens apresentaram valores sempre maiores que os da floresta durante a estação seca. Esse aumento da umidade do solo sobre o uso de pastagens implica em maior percolação de água rumo ao lençol freático. Este fato aliado à maior produção de escoamento superficial nos menos frequentes eventos pluviais de alta intensidade explica os maiores valores do coeficiente de deflúvio. Dessa forma, espera-se uma maior conversão de chuva em vazão em termos anuais, ao converter uma microbacia coberta por floresta tropical atlântica em pastagem. Todavia, o aumento do deflúvio ocorre em detrimento da altíssima diversidade biológica e da alta proteção do solo que ocorre quando o solo está coberto por florestas.

\section{AGRADECIMENTOS}

Os autores gostariam de agradecer ao Fundação de Amparo à Pesquisa no Estado de São Paulo (FAPESP) pelo financiamento da presente pesquisa (processos 2006/54292-9 e 2006/55136-0). Além disso, os autores agradecem João Paulo Villani (gestor do núcleo Santa Virgínia pertencente ao Parque Estadual da Serra do Mar) e todos os seus funcionários cuja dedicação tornou esta pesquisa possível.

\section{REFERENCIAS}

ANIDO, N. M. R. Caracterização hidrológica de uma microbacia experimental visando identificar indicadores de monitoramento ambiental. 2002. 69 f. Dissertação (Mestrado em Recursos Florestais) - Escola Superior de Agricultura Luiz de Queiroz, Universidade de São Paulo, Piracicaba, 2002.

ARCOVA, F. C. S.; CICCO, V. Características do deflúvio de duas microbacias hidrográficas no laboratório de hidrologia florestal Walter Emmerich, Cunha - SP. Revista Instituto Florestal, São Paulo, v. 9, p. 153-170, 1997.

ARCOVA, F. C. S.; CICCO, V. de; ROCHA, P. A. B. Precipitação efetiva e interceptação das chuvas por floresta de mata atlântica em uma microbacia experimental em Cunha São Paulo. Revista Árvore, Viçosa, MG, v. 27, n.2, p. 257-262, 2003. http://dx.doi.org/10.1590/S0100-67622003000200014

BIGGS, T. W.; DUNNE, T.; MURAOKA, T. Transport of water, solutes and nutrients from a pasture hillslope, southwestern Brazilian Amazon. Hydrological Processes, Bristol, v. 20, n. 12, p.2527-2547, 2006. http://dx.doi.org/10.1002/hyp.6214

BROWN, A. E.; ZHANG, L.; McMAHON, T. A.; WESTERN, A. W.; VERTESSY, R. A. A review of paired catchment studies for determining changes in water yield resulting from alteration in vegetation. Journal of Hydrology, Amsterdam, v. 310, n. 1/4, p. 2861, 2005. http://dx.doi.org/10.1016/j.jhydrol.2004.12.010

BUENO, E. Capitães do Brasil: a saga dos primeiros colonizadores. 2. ed. Rio de Janeiro: Objetiva, 2006. 258p. 
SALEMI, L. F.; GROPPO, J. D.; TREVISAN, R.; SEGHESI, G. B.; MORAES, J. M.; FERRAZ, S. F. B.; MARTINELLI, L. A. Consequências hidrológicas da mudança de uso da terra de floresta para pastagem na região da floresta tropical pluvial atlântica. Ambi-Agua, Taubaté, v. 7, n. 3, p. 127-140, 2012. (http://dx.doi.org/10.4136/ambi-agua.927)

CHOW, V. T.; MAIDMENT, D. R.; MAYS, L. W. Applied hydrology. New York: McGraw-Hill Book, 1988. 572p.

COELHO NETO, A. L. Overland flow production in a tropical rainforest catchment: the role of litter cover. Catena, Amsterdam, v. 14, n. 1/3, p. 213-231, 1987. http://dx.doi.org/ 10.1016/S0341-8162(87)80019-X

DEAN, W. A ferro e fogo: a história e a devastação da Mata Atlântica brasileira. São Paulo: Companhia das Letras, 1996. 484p.

DONATO, C. F.; RANZINI, M.; CICCO, V.; ARCOVA, F. C. S.; SOUZA, L. F. S. Balanço de massa em microbacia experimental com Mata Atlântica, na Serra do Mar, CunhaSP. Revista do Instituto Florestal, São Paulo, v. 20, n. 1, p. 1-11, 2008.

DUNNE, T. Field studies of hillslope flow process. In: KIKBY, M. J. (Ed.). Hillslope hydrology. Chichester: John Wiley, 1978. p. 227-293.

ELSENBEER, H.; NEWTON, B. E.; DUNNE, T.; MORAES, J. M. Soil hydraulic conductivities of latosols under pasture, forest and teak in Rondônia, Brazil. Hydrological Processes, Bristol, v. 13, n. 9, p. 1417-1422, 1999. http://dx.doi.org/10.1002/(SICI)1099-1085(19990630)13:9<1417::AID-HYP816>3.0.CO;2-6

FOLHES, M. T.; RENNÓ, C. D.; FISCH, G. Caracterização espaço-temporal do regime pluviométrico na parte paulista da bacia hidrográfica do rio Paraíba do Sul. In: SEMINÁRIO DE RECURSOS HÍDRICOS DA BACIA HIDROGRÁFICA DO PARAÍBA DO SUL: O EUCALIPTO E O CICLO HIDROLÓGICO,1., 7-9 nov., 2007, Taubaté. Anais... Taubaté: IPABHi, 2007. p. 359-361.

FUJIEDA, M.; KUDOH, T.; CICCO, V.; CALVARCHO, J. L. Hydrological processes at two subtropical forest catchments: the Serra do Mar, São Paulo, Brazil. Journal of Hydrology, Amsterdam, v. 196, n. 1/4, p. 26-46, 1997. http://dx.doi.org/10.1016/ S0022-1694(97)00015-2

GERMER, S.; NEILL, C.; VETTER, T.; CHAVES, J.; KRUSCHE, A. V.; ELSENBEER, H. Implications of long-term lad-use change for the hydrology and solute budgets of small catchments in Amazonia. Journal of Hydrology, Amsterdam, v. 364, n. 3/4, p. 349363, 2009.

GODSEY, S.; ELSENBEER, H. The soil hydrologic response to forest regrowth: a case study from southwestern Amazonia. Hydrological Processes, Bristol, v. 16, n. 7, p. 1519-1522, 2002. http://dx.doi.org/10.1002/hyp.605

GROPPO, J. D. Caracterização hidrológica e dinâmica do nitrogênio em uma microbacia com cobertura florestal (Mata Atlântica), no Parque Estadual da Serra do Mar, núcleo Santa Virgínia. 2010. 80 f. Tese (Doutorado em Ciências) Centro de Energia Nuclear na Agricultura, Universidade de São Paulo, Piracicaba, 2010.

GWINN, W. R.; PARSONS, D. A. Discharge equations for HS, H, and HL flumes. Journal of Hydraulics Division, Ithaca, v. 102, n. 1, p.73-88, 1976.

HEWLETT, J. D. Principles of forest hydrology. Athens: The University of Georgia Press, 1982. 183p. 
SALEMI, L. F.; GROPPO, J. D.; TREVISAN, R.; SEGHESI, G. B.; MORAES, J. M.; FERRAZ, S. F. B.; MARTINELLI, L. A. Consequências hidrológicas da mudança de uso da terra de floresta para pastagem na região da floresta tropical pluvial atlântica. Ambi-Agua, Taubaté, v. 7, n. 3, p. 127-140, 2012. (http://dx.doi.org/10.4136/ambi-agua.927)

HODNETT, M. G.; PIMENTEL DA SILVA, L.; ROCHA, H. R.; CRUZ SENNA, R. Seasonal soil water storage changes beneath central Amazonian rainforest and pasture. Journal of Hydrology, Amsterdam, v.170, n. 1/4, p.233-254, 1995. http://dx.doi.org/10.1016/0022-1694(94)02672-X

JIPP, P. H.; NEPSTAD, D. C.; CASSEL, D. K.; REIS DE CARVALHO, C. Deep soil moisture storage and transpiration in forests and pastures of seasonally-dry Amazonia. Climatic Change, Amsterdam, v. 39, n. 2/3, p. 395-412, 1998. http://dx.doi.org/10.1023/A:100508930871

MORAES, J. M.; SCHULER, A. E.; DUNNE, T.; FIGUEIREDO, R. O.; VICTORIA, R. L. Water storage and runoff processes in plinthic soils under forest and pasture in eastern Amazonia. Hydrological Processes, Bristol, v. 20, n. 12, p. 2509-2526, 2006. http://dx.doi.org/10.1002/hyp.6213

MORAES, J. F.; VOLKOFF, B.; CERRI, C. C.; BERNOUX, M. Soil properties under Amazon forest and changes due to pasture installation in Rondônia, Brazil. Geoderma, Amsterdam, v. 70, n. 1, p. 63-81, 1996. http://dx.doi.org/10.1016/0016-7061(95)00072-0

MORELlATO, L. P. C.; HADDAD, C. F. B. Introduction: the brazilian Atlantic Forest. Biotropica, Bristol, v. 32, n. 4b, p. 786-792, 2000. http://dx.doi.org/10.1111/j.17447429.2000.tb00618.x

NEPSTAD, D. C.; CARVALHO, C. R.; DAVIDSON, E. A.; JIPP, P. H.; LEFEBVRE, P. A.; NEGREIROS, G. H. et al. The role of deep roots in the hydrological and carbon cycles of Amazonian forests and pastures. Nature, London, v. 372, p. 666-669, 1994. http://dx.doi.org/10.1038/372666a0

RANZINI, M.; RIGHETTO, A. M.; LIMA, W. P.; GUANDIQUE, M. E. G.; ARCOVA, F. C. S.; CICCO, V. Processos hidrológicos de uma microbacia com Mata Atlântica, na região da Serra do Mar, SP. Scientia Forestalis, Piracicaba, v. 66, p. 108-119, 2004a.

RANZINI, M.; RIGHETTO, A. M.; GUANDIQUE, M. E. G.; MORAES, J. M.; ARCOVA, F. C. S.; CICCO, V. Modelagem hidrológica de uma microbacia florestada da Serra do Mar, SP. Revista Brasileira de Recursos Hídricos, Porto Alegre, v. 9, n. 4, p. 33-44, 2004b.

REICHARDT, K. Capacidade de campo. Revista Brasileira de Ciência do Solo, Viçosa, MG, v. 12, p. 211-216, 1988.

REINERS, W. A.; BOWMAN, A. F.; PARSONS, W. F. J.; KELLER, M. Tropical rain forest conversion to pasture: changes in vegetation and soil properties. Ecological Applications, Ithaca, v. 4, p. 363-377, 1994. http://dx.doi.org/10.2307/1941940

SALEMI, L. F. Balanço de água e de nitrogênio em uma microbacia coberta por pastagem no litoral Norte do Estado de São Paulo. 2009. 87 f. Dissertação (Mestrado em Ecologia Aplicada) - Centro de Energia Nuclear na Agricultura / Escola Superior de Agricultura "Luiz de Queiroz", Universidade de São Paulo, Piracicaba, 2009.

SCHÄFFER, W. B.; PROCHNOW, M. Mata Atlântica: informações gerais. In: SCHÄFFER, W.B.; PROCHNOW, M. (Org.). A Mata Atlântica e você: como preservar, recuperar e se beneficiar da mais ameaçada floresta brasileira. Brasília: APREMAVI, 2002. p. 1213. 
SALEMI, L. F.; GROPPO, J. D.; TREVISAN, R.; SEGHESI, G. B.; MORAES, J. M.; FERRAZ, S. F. B.; MARTINELLI, L. A. Consequências hidrológicas da mudança de uso da terra de floresta para pastagem na região da floresta tropical pluvial atlântica. Ambi-Agua, Taubaté, v. 7, n. 3, p. 127-140, 2012. (http://dx.doi.org/10.4136/ambi-agua.927)

ZHANG, L.; DAWES, W. R.; WALKER, G. R. The response of mean annual evapotranspiration to vegetation changes at the catchment scale. Water Resources Research, New York, v. 37, p. 701-708, 2001. http://dx.doi.org/10.1029 /2000WR900325

ZIMMERMANN, B.; ELSENBEER, H.; MORAES, J. M. The influence of land-use change on soil hydraulic properties: implications for runoff generation. Forest Ecology and Management, Amsterdam, v. 222, n. 1/3, p. 29-39, 2006. http://dx.doi.org/ 10.1016/j.foreco.2005.10.070 